\title{
EVALUATION OF THE NEUROPROTECTIVE EFFECT OF KETOPROFEN ON RATS SUBMITTED TO PERMANENT FOCAL BRAIN ISCHEMIA
}

\author{
Manoel Nunes da Silva', Benedicto Oscar Colli2, \\ Norberto Cysne Coimbra ${ }^{3}$, Joaquim Coutinho Netto ${ }^{4}$
}

\begin{abstract}
Objective: To study the neurobehavioral, biochemical and histopathological consequences of permanent focal brain ischemia, and the putative neuroprotective action of ketoprofen. Method: Onehundred-and-three Wistar rats divided into groups A and B were respectively submitted to 48 hours and 15 days of ischemia. Each group was divided into 4 subgroups: ischemic not treated, ischemic treated, sham not treated, and sham treated. Ischemic animals had the left middle cerebral artery coagulated. Ketoprofen was administered to treated subgroups 15 minutes before arterial coagulation (manipulation in the sham group). Results: Exploratory activity and defecation were reduced in all ischemic animals in the first postoperative days and constant histopathological changes were observed in each group. The total brain glutamate levels were higher in treated animals 48 hours after surgery. Conclusion: No clear parallelism among behavioral, biochemical and histopathological findings was observed. Ketoprofen demonstrated no neuroprotective effect on the behavioral or histopathological aspects of focal permanent brain ischemia.
\end{abstract}

KEY WORDS: focal brain ischemia, rat, open field, glutamate, histopathology, neuroprotection, ketoprofen.

\begin{abstract}
Avaliação do efeito neuroprotetor do cetoprofeno em ratos submetidos à isquemia cerebral focal permanente

RESUMO - Objetivo: Estudar as conseqüências comportamentais, bioquímicas e histopatológicas da isquemia cerebral focal permanente e o possível efeito neuroprotetor do cetoprofeno. Método: Foram utilizados 103 ratos Wistar, divididos em grupos A e B, submetidos, respectivamente, a 48 horas e a 15 dias de isquemia. Cada grupo foi dividido em 4 subgrupos: isquêmico não tratado; isquêmico tratado; sham não tratado; sham tratado. Nos animais isquêmicos foi coagulada a artéria cerebral média esquerda. Os subgrupos tratados receberam cetoprofeno 15 minutos antes da oclusão ou manipulação arterial. Resultados: Os animais isquêmicos reduziram a atividade exploratória e as evacuações nos primeiros dias pós-operatórios e mostraram alterações histopatológicas constantes em cada grupo. As concentrações do glutamato total 48 horas após a cirurgia foram maiores nos animais tratados. Conclusão: Não houve um paralelismo entre os achados comportamentais, bioquímicos e histopatológicos. O cetoprofeno não apresentou efeito protetor contra isquemia cerebral focal permanente, nos aspectos comportamentais e histopatológicos.
\end{abstract}

PALAVRAS-CHAVE: isquemia cerebral focal, rato, open field, glutamato, histopatologia, neuroproteção, cetoprofeno.

Cerebral ischemia $(\mathrm{Cl})$ is a frequent condition in daily clinical practice and is an important cause of morbidity and mortality. In neurosurgical practice, $\mathrm{Cl}$ is common after subarachnoid hemorrhage, in lesions secondary to cranioencephalic traumatism and in neurovascular procedures with temporary clipping. Clinical research on cerebral ischemia is limited and studies aiming at the understanding of its physiopathology and treatment are usually experimental. Rats are extensively used in these experimental studies because of the morphofunctional similarities of their brain circulation to that of humans ${ }^{1-4}$. In addition to routine neurological examinations, experimental studies on the behavior of rats in the open field, extensively used in neuropsychobiological studies, less frequently has been used to assess the effects of cerebral ischemia ${ }^{5,6}$.

Glutamate, the main excitatory neurotransmitter (NT) in the central nervous system (CNS), is the most important factor aggravating the loss of ionic homeostasis during anoxic-ischemic encephalopathy?.

Division of Neurosurgery, Department of Surgery and Anatomy, Ribeirão Preto Medical School, University of São Paulo, Ribeirão Preto SP, Brazil: 'Assistant Physician, Division of Neurosurgery; ${ }^{2}$ Professor of Surgery, Head of the Division of Neurosurgery; ${ }^{3}$ Assistant Professor, Department of Pharmacology; ${ }^{4}$ Associate Professor, Department of Biochemistry. Research supported by CAPES.

Received 13 March 2007, received in final form 29 June 2007. Accepted 9 August 2007. 
In the presence of ischemic injury, glutamate increases rapidly in the extracellular space ${ }^{8}$, provoking sodium and especially calcium inflow through ion channels having N-methyl D-aspartate (NMDA) as an agonist. The increased cytoplasmic calcium concentration triggers a cascade of inflammatory reactions that may progress to cell death. Non-hormonal anti-inflammatory agents may have a neuroprotective (NP) effect by blocking the inflammatory response triggered by the ischemic phenomenon, a hypothesis that was confirmed by the reduction in the amount of glutamate released in the cerebral cortex of rats submitted to ischemia and treated with indomethacin ${ }^{9}$. Ketoprofen was demonstrated to have much more potent analgesic and anti-inflammatory actions ${ }^{10}$, acting centrally as a possible antagonist of NMDA receptors, preventing central sensitization and abolishing the hypersensitivity already installed"1". Its NP effect has been attributed to antagonism of the reduction of acetylcholine receptors $^{12}$. A recent study carried out at our institution has confirmed the NP action of this drug ${ }^{13}$.

The objective of the present study was to contribute to the understanding of the pathophysiology and treatment of $\mathrm{Cl}$, with the following main goals: (a) to evaluate the behavioral, biochemical and histopathological parameters of the model, and (b) to evaluate the possible NP effect of ketoprofen on experimental permanent focal ischemia.

\section{METHOD}

A total of 127 Wistar rats weighing 280 to $430 \mathrm{~g}$ were used. The animals were kept in an animal facility before and after surgery, with free access to ration and water. Rules for the prevention of animal suffering were followed during the procedures ${ }^{14,15}$. Twelve ( $\left.9.5 \%\right)$ animals, similarly distributed in groups $A$ and $B$, died during surgery, 9 due to respiratory depression caused by excessive ether inhalation and 3 because of severe hypotension due to blood loss. All cases had cardiorespiratory arrest before the craniotomy was performed and they suffered global cerebral ischemia that could mislead the effects of the focal ischemia.

Twelve (9.5\%) animals from group B (assessment 15 days after the ischemia), developed postoperative wound infections starting in the third postoperative day, manifested by local suppuration and general compromise. In all cases subdural empiema and/or brain abscess were observed macroscopically (8 cases) or on the histopathologic preparations ( 4 cases).

Experimental groups - The animals were divided at random into two groups according to the duration of ischemia: in group $A$ the effects of ischemia were evaluated in 59 animals with and without neuroprotection after 48 hours, and in group B the effects of ischemia were evaluated after 15 days. Each group was divided into 4 subgroups: ischemic not treated (INT-A and B - 12 animals each), ischemic treated (IT-A, 16 animals and IT-B, 8 animals), sham not treated (NINT-A, 16 animals and NINT-B, 13 animals), and sham treated (NIT-A, 15 animals and NIT-B, 11 animals). The animals of the ischemic subgroups were submitted to coagulation of the left middle cerebral artery (MCA) and the animals of the treated subgroup received ketoprofen, $10 \mathrm{mg} / \mathrm{kg}$, by the intravenous route, 15 minutes before coagulation (ischemic subgroups) or arterial manipulation (sham subgroups).

Preoperative evaluation - Each animal was weighed immediately before the surgical procedure. Before surgery, 24 animals from group $A$ and 44 from group $B$ were observed and filmed in an open field ${ }^{16}$ for 15 minutes for behavioral evaluation. The following items were analyzed: a) number of crossings (passing from one section of the open field to another), number of defecations (number of fecal boluses during the period), number of rearings of the front paws and of half rotations ( $180^{\circ}$ turns); b) rates of sniffing (exploration of the environment by olfaction), of grooming (selfcleaning) and resting (immobility in the same place). These indices were arbitrarily assigned a score of 1 point for each uninterrupted period of 10 seconds during which the animal engaged in that behavior. The observations were always made at night by the same observer and under the same environmental conditions.

Coagulation of the left MCA - The MCA was approached under ether inhalation anesthesia and spontaneous respiration using the technique described by Tamura et al. ${ }^{1}$, modified $^{17-19}$. No antibiotics or skin antisepsis were used. Mean arterial pressure and heart rate were recorded using a catheter introduced into the caudal artery and kept at normal values ( 90 to $100 \mathrm{~mm} \mathrm{Hg}$ and 300 to 360 beats per minute, respectively $)^{20}$. Temperature was monitored with a rectal thermometer and remained at about $36.5^{\circ} \mathrm{C}$, with no need for external heating.

The frontal and temporal bones and the zygomatic arch were exposed through a $1.5 \mathrm{~cm}$ vertical incision. The zygomatic arch was resected with a rongeur and the mandibular condyle was exposed and pushed back together with the muscle tissues using cotton balls until the oval foramen was exposed. A craniectomy measuring $5 \mathrm{~mm}$ in diameter was performed ventrally to the oval foramen, the dura mater was opened and the cerebral cortex was slightly dislocated with a cotton ball in order to expose the proximal region of the MCA. A microclip (Yasargil FD - 710 clip, Aesculap) was applied to the proximal portion of the MCA, followed by bipolar coagulation of the segment between the olfactory tract and the crossing with the ventral cerebral vein. The microclip was then removed and the muscle plane and the skin were sutured.

Postoperative evaluation - Weight was measured and behavior in the open field was again evaluated in 55 animals of group $A$ and 44 animals of group $B$ on the 1st (groups $A$ and $B$ ) and on the 7 th and 14th (group B) postoperative days. Group A animals were sacrificed 48 hours after surgery and group B animals were sacrificed 15 days after surgery. 
Biochemical evaluation (glutamate determination) - Total glutamate was determined in 26 animals of group $A$ (INT-A - 5, IT-A - 8, NINT-A - 5 and NIT-A 8) and in 22 animals of group B (INT-B - 6, IT-B - 5, NIT-B - 7 and NINT-B - 4).

The animals were sacrificed by strangulation and the brains were removed fresh, without perfusion or fixation. Immediately after removal, fragments of the caudate-putamen region of each brain hemisphere were obtained, individually placed in a $0.5 \mathrm{~mL}$ solution of hydrochloric acid 0.01 normal, and stored in a freezer at $-20^{\circ} \mathrm{C}$. The samples were submitted to high performance liquid chromatography using a chromatograph equipped with a SHIMADZU high pressure pump (LC-7A), a manual Rheodyne injector, a $50 \mu \mathrm{L}$ loop, an LDC fluorometric detector, and a Beckman-427 integrator-recorder. A reverse-phase column (100x4 $\mathrm{mm})$, ODS-C18 Hibar-Supersphere $5 \mu \mathrm{m}$ (Merck) and a precolumn (4X10 mm) packed with Perisorb ODS-C18 (Merck) in our laboratory were used. The method of pre-reaction with o-phtalaldehyde (OPA) described by Lindroth and Mopper ${ }^{21}$, modified, was used. The result obtained by this method expresses the value of glutamate concentration per unit of brain tissue mass.

Histopathologic analysis - Histopathologic analyses were performed in 30 animals of group A (INT-A - 7, IT-A - 8, NIT-A - 8 and NINT-A - 7), and 16 animals of group B (INT-B - 4, IT-B - 3, NIT-B - 4 and NINT - 5).

The animals were sacrificed by massive ethyl ether inhalation and perfused transcardiacly with $0.1 \mathrm{M}$ phosphate buffered saline solution, $\mathrm{pH} 7.3$, at $4^{\circ} \mathrm{C}$, followed by $4 \%$ paraformaldehyde in $0.1 \mathrm{M}$ phosphate buffer, $\mathrm{pH} 7.3$, after occlusion of the abdominal aorta. The brains were then removed, immersed in $4 \%$ paraformaldehyde fixing solution for 4 hours, frozen at $-70^{\circ} \mathrm{C}$ and cut into $40 \mu \mathrm{m} \mathrm{sec}-$ tions in the craniocaudal direction from the prefrontal region to the mesencephalon with a cryostat (MCIROM, Type $\mathrm{HM} 505 \mathrm{EP}, \mathrm{Germany})$ at $-20^{\circ} \mathrm{C}$. The sections were stained with Giemsa and analyzed qualitatively under the light microscope for the identification of the injured structures and of the type of injury based on the atlas of Paxinos and Wat- son $^{22}$. Next, the sections were photographed with an Axiophot Zeiss microscope.

Statistical analysis - The variables for each group were analyzed by the Student $t$-test (weight) and the nonparametric Wilcoxon test (behavioral variables and glutamate determinations). Inter-group comparisons were made using analysis of variance (ANOVA) followed by the Tukey post-test (weight) and the nonparametric Kruskal-Wallis test followed by the Dunn post-test (behavioral variables and glutamate determinations). Levels of less than $5 \%$ for twotailed tests were considered significant. The statistical tests were carried out using the GrapPad Prism ${ }^{\circledR} 3$ software, San Diego, CA, USA.

\section{RESULTS}

Motor deficits - Gross postoperative observation of gait and movements showed that all animals submitted to MCA coagulation had hemiparesis contralateral to the ischemic hemisphere, clearly observed just after the animals waked up from the anesthetic procedure and remaining for the first 6 to 12 hours.

Weight changes - There was a tendency to weight loss on the $1^{\text {st }}$ postoperative day, with all subgroups but one losing weight. This was more marked in ischemic than in sham and untreated animals (INT-A-B $>$ NINT-A-B = NIT-A-B, $p=0.02$, ANOVA followed by the Tukey post-test). Temporal analysis of each subgroup showed weight gain in all of them between the 1st and 14th postoperative days ( $p<0.05$, Student $t$-test) and between the $7^{\text {th }}$ and $14^{\text {th }}$ postoperative days ( $p<0.05$, Student $t$-test).

Behavioral changes - No differences were observed between subgroups (Kruskal-Wallis test) regarding number of episodes of crossing, defecation,
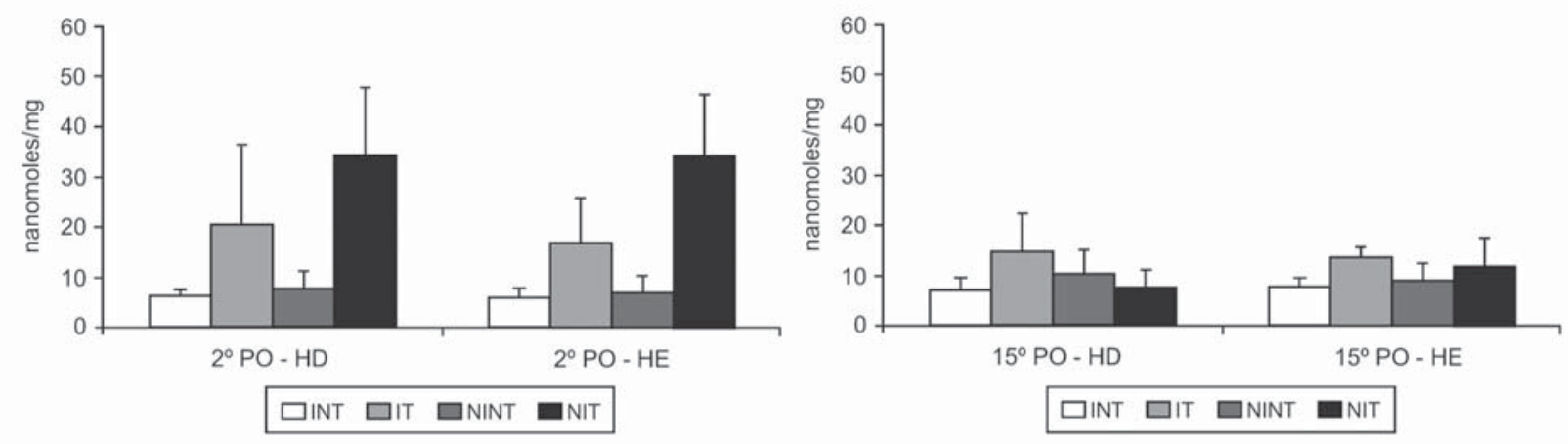

Fig 1. Determination of glutamate in the two brain hemispheres of the animals of group A (sacrifice after 48 hours of ischemia - upper graph) and of group B (sacrifice after 15 days of ischemia - lower graph) and of their subgroups. RH, right hemisphere; $L H$, left hemisphere; INT, ischemic not treated; IT, ischemic treated; NINT, sham not treated; NIT, sham treated; PO, postoperative. 
Table. Total glutamate concentrations in the two brain hemispheres of rats. Data are reported as means $\pm S D$ in $\mu g / m L$.

\begin{tabular}{|c|c|c|c|c|}
\hline \multirow{3}{*}{$\begin{array}{l}\text { Groups } \\
\text { Sub-groups }\end{array}$} & \multicolumn{4}{|c|}{ Sacrifíce after Ischemia } \\
\hline & \multicolumn{2}{|c|}{ A (48 Hours) } & \multicolumn{2}{|c|}{ B (15 Days) } \\
\hline & Right hemisphere & Left hemisphere & Right hemisphere & Left hemisphere \\
\hline INT & $6.30 \pm 1.43^{*}$ & $5.95 \pm 1.86^{*}$ & $7.14 \pm 2.42$ & $7.62 \pm 1.77^{*}$ \\
\hline IT & $20.55 \pm 16.20$ & $16.70 \pm 8.91^{*}$ & $14.71 \pm 7.88$ & $13.61 \pm 1.96^{*}$ \\
\hline NINT & $7.50 \pm 3.84^{*}$ & $7.04 \pm 3.21 *$ & $10.41 \pm 4.75$ & $9.04 \pm 3.35$ \\
\hline NIT & $34.40 \pm 13.45^{*}$ & $33.94 \pm 12.58$ * & $7.60 \pm 3.51$ & $11.63 \pm 5.74$ \\
\hline
\end{tabular}

INT, ischemic not treated; IT, ischemic treated; NINT, sham not treated; NIT, sham treated; *RH Group A: NIT>INT=NINT p<0.006 (Kruskal-Wallis test followed by the Dunn post-test); *LH Group A: NIT>INT=NINT=IT ( $p=0.01$, Kruskal-Wallis test followed by the Dunn post-test); *LH Group B: IT >INT ( $p=0.04$, Kruskal-Wallis test followed by the Dunn post-test).

sniffing, resting, rearing, half rotation, and grooming ( $p<0.05$ for all) for the same period. The temporal evolution of each subgroup revealed a reduction (Wilcoxon test) of exploratory activity (sniffing and rearing) and of defecations $(\mathrm{p}<0.05)$ on the $1^{\text {st }}$ postoperative day in the ischemic subgroups.

Glutamate determination - Total glutamate concentrations were similar in the right and left brain hemispheres in all subgroups (INT-A, $p=0.89$; INT-B, $\mathrm{p}=0.25$; IT-A, $\mathrm{p}=0.48$; IT- $\mathrm{B}, \mathrm{p}=0.89$; NINT-A, $\mathrm{p}=0.75$; NINT-B, $p=0.50$; NIT-A, $p=0.67$ and NIT-B, $p=0.07$, Wilcoxon test). Comparison of the subgroups after 48 hours of ischemia showed higher values in the two brain hemispheres of treated animals [NIT-A > IT-A, INT-A and NINT-A on the right $(p<0.006)$, and NIT-A $>$ INT-A $=$ NINT-A $=$ IT-A, on the left $p=0.01$, KruskalWallis test followed by the Dunn post-test)], with a significant elevation in the sham subgroup. After 15 days of ischemia there was no difference in the right brain hemisphere between the animals of the various subgroups (INT-B = IT-B = NINT-B = NIT-B, $p=0.18$; Kruskal-Wallis test), and the levels were higher in the left brain hemisphere in the treated and untreated ischemic subgroups ( $p=0.04$, Kruskal-Wallis test followed by the Dunn post-test) (Fig 1 and Table 1).

Histopathological changes - These alterations were constant in ischemic animals regardless of whether or not they had been treated (Figs 2 and 3 ). The injured region was the same in groups $A$ and $B$, always presenting well-defined limits. Extensive cortical and subcortical lesions were observed. In the rostrocaudal direction, the following cortical areas were injured: primary motor, insula, piriform, lateral and ventral orbital, primary sensory of the mandibular region, of the fore and hind legs and barrel field, in addition to the cingulate gyrus. The following subcortical structures were involved: nucleus accumbens, anterior commissure, claustrum, the knee of the cor-

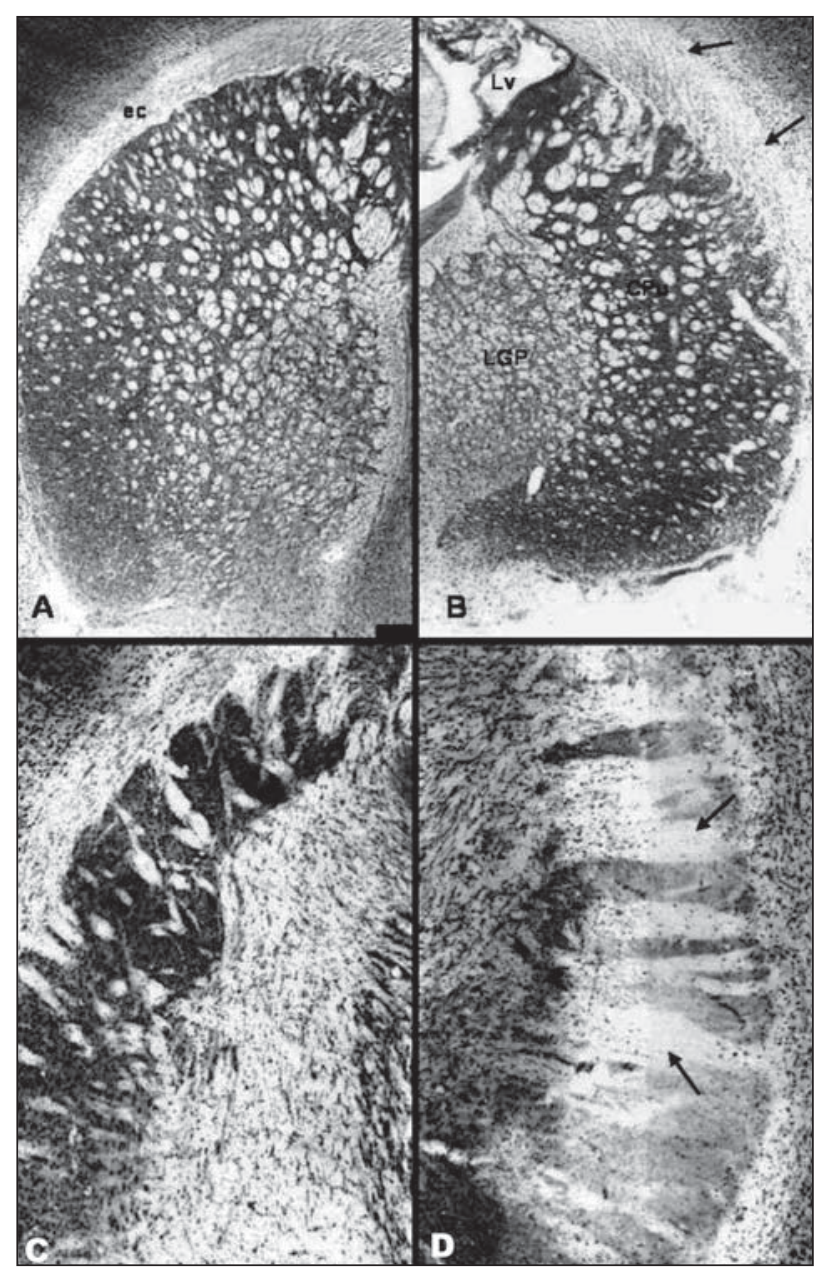

Fig 2. Photomicrographs of coronal sections of the brain of the same rat passing through the corpus striatum at a more cranial ( $A$ and $B$ ) and more caudal ( $C$ and $D$ ) level. The brain was removed 48 hours after coagulation of the left middle cerebral artery, without treatment with ketoprofen. The structures of the injured brain hemisphere are shown in $B$ and $D$, while $A$ and $C$ show the control side. Note (arrows) the areas of expressive neuronal rarefaction, mainly identified in the caudal neostriatum (D) and in the internal capsule (B), with relative preservation of the cranial part of the caudate-putamen. $C P u$, caudateputamen; ec, external capsule; LGP, lateral part of the globus pallidus; $L v$, lateral ventricle. Staining: Giemsa. Bar: $385 \mu \mathrm{m}$ in $A$ and $B, 192 \mu \mathrm{m}$ in $C$ and $96 \mu \mathrm{m}$ in $D$. 


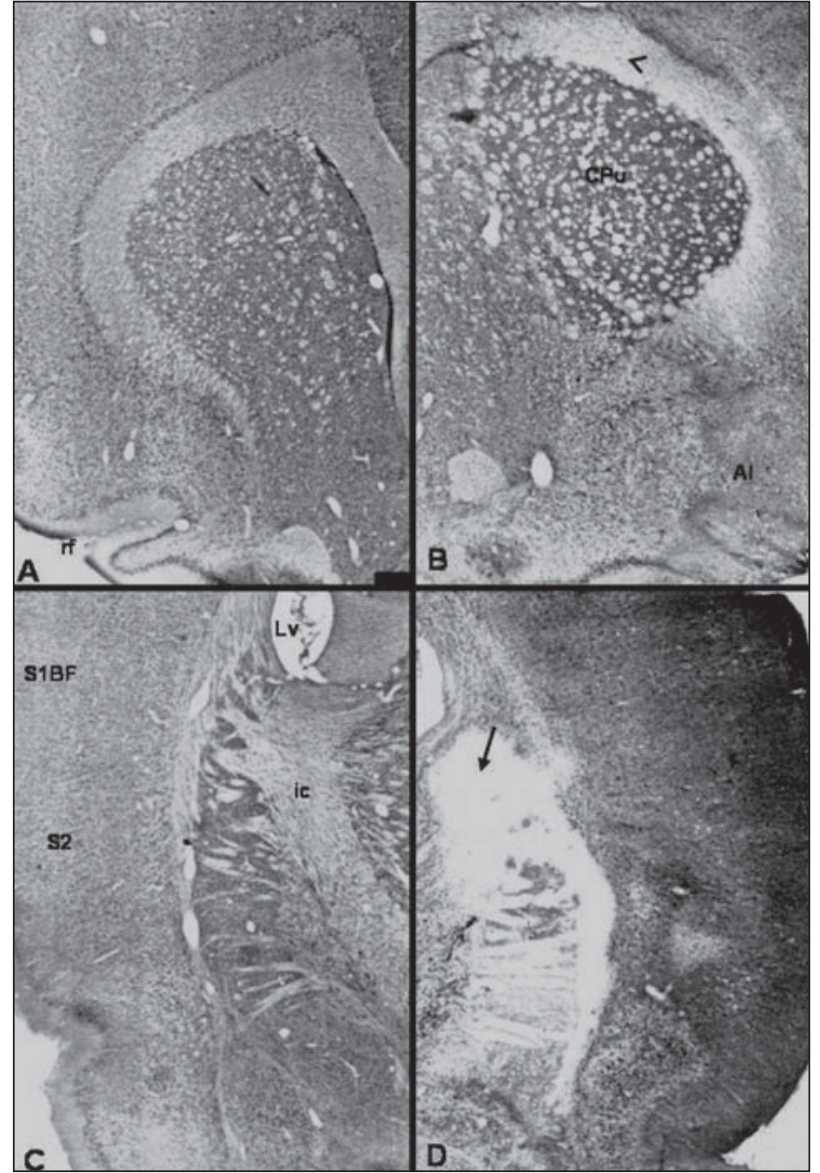

Fig 3. Photomicrographs of coronal sections of the brain of the same rat passing through the corpus striatum at a more cranial ( $A$ and $B$ ) and more caudal ( $C$ and $D$ ) level. The brain was removed 48 hours after coagulation of the left middle cerebral artery, with the animal having received ketoprofen by the intravenous route at the dose of $10 \mathrm{mg} / \mathrm{kg}$ of body weight $15 \mathrm{~min}$ utes before coagulation. The injured brain hemisphere is shown in $B$ and $D$ and the control in $A$ and $C$. Observe in $B$ the intense hypercellularity of the external capsule (arrowhead), as well as less intense cell rarefaction in the caudate-putamen region and in the insula. Note in D total cell loss in most of the caudateputamen (arrow), and more discrete hypocellularity in the adjacent sensorimotor cortex. Al, agranular cortex of the insula; CPu, caudate putamen; ec, external capsule; ic, internal capsule; $L v$, lateral ventricle; $r f$, rhinal fissure; $S_{1} B F$, primary sensory cortex, barrel field; S2, secondary sensory cortex. Staining: Giemsa. Bar: $385 \mu \mathrm{m}$.

pus callosum, the caudate-putamen region, the lateral globus pallidus, the external capsule, temporal amygdala, and fimbria of the hippocampus. Clearly visible hypercellularity was detected in group A ( 48 hours), with neutrophil exudation at the periphery of the lesion, in addition to white matter edema in homolateral ventricular collapse. Some sections presented necrosis with loss of tissue in small areas. Intense small cell hypercellularity possibly corresponding to reactional gliosis, lymphocytes or macrophages was observed in group B. Necrosis and loss of tissue, volumetric reduction of the cortex with ipsilateral ventricular dilatation ex-vacuo and destructuring of the cortical architecture were frequently observed.

In the animals of the sham subgroups ( $A_{3}$ and $\left.B_{3}\right)$, no injuries were observed in either hemisphere.

\section{DISCUSSION}

$\mathrm{Cl}$ is a complex multifactorial phenomenon whose treatment depends on a better understanding of its pathophysiology. For this purpose, studies with a rigorous evaluation and control of multiple variables are necessary, mainly using experimental models ${ }^{1,2,23}$. Twelve (9.5\%) animals died during the surgical procedure and were excluded from the study because they presented prior cardiorespiratory arrest and suffered global cerebral ischemia that misleads the results of the focal ischemia. In the same way, patients that developed subdural empiema and or brain abscess were excluded from the study. We believe that most operative death could be avoided using controlled mechanical ventilation. Antiseptic measures and antibiotics prophylaxis could reduce significantly the postoperative infections.

Variations in body weight have been used in recent studies as a parameter to evaluate transitory focal cerebral ischemia ${ }^{24,25}$. The administration of progesterone before 2 hours of ischemia and after 48 hours of reperfusion was responsible for a smaller weight loss ${ }^{24}$. The administration of lidocaine before ischemia followed by 7 days of reperfusion caused a lower weight loss on treated animals than in controls ${ }^{25}$. The weight reduction observed in the present study may be attributed to the surgical procedure and to anesthesia.

The open field has been little used to assess the effects of $\mathrm{Cl}$. This was used in this study because it was the only way we find to assess behaviors as crossing, defecation, sniffing, resting, rearing, half rotation, and grooming and because it was available and validated in our facility ${ }^{16}$. The time of observation was arbitrarily fixed in 15 minutes after some previous observations that the exploratory activity of the animals decreased progressively after 5 to 10 minutes. The first postoperative assessment was performed during the first postoperative day, because at that time the motor deficit had completed released.

Once there were marked cortical and subcortical histopathological changes, more severe motor deficit and behavior disturbances were expected and we did not find explanation for this fact. 
Comparison of MCA ligation on the right $x$ the left in rats showed that only the animals with ischemia on the right presented hyperactivity for 2 to 3 weeks ${ }^{26}$.

The use of ketamine in rats before occlusion of the right MCA did not cause behavioral differences (number of crossings, rearings and defecations) between treated and untreated animals, although no NP effect of the drug was detected based on the histopathological findings ${ }^{5}$. Another study did not detect correspondence between the behavioral and histopathological effects provoked by coagulation of the MCA in rats $^{6}$. Using the open field test according to the criteria established at our institution ${ }^{16}$, we observed reduction of exploratory activity (rearing and sniffing) and of defecation on the 1st postoperative day in all animals of the ischemic groups. Despite differences in the elaboration and execution of the tests, our results agree with those reported by Wahl et al. ${ }^{6}$ regarding the absence of a correlation between the behavioral and histopathological changes.

The involvement of glutamate in brain injury was confirmed in 1981, when it was demonstrated that one of its antagonists, amino-phosphono-butyric acid, reduced or prevented the epileptic manifestations artificially produced in rats $^{27}$. Later, Benveniste et al. ${ }^{8}$ observed an increase in glutamate in the hippocampus of rats after ischemia. Baker et al. ${ }^{28}$ detected slower, less intense and shorter lasting elevation of glutamate in the ischemic hemisphere of hypothermic animals, in agreement with findings of lower histological injury. A recent study from our institution using permanent focal $\mathrm{Cl}$ in rats demonstrated a progressive reduction in total glutamate levels on the injured side after 30 and 45 minutes, which was not influenced by previous ketoprofen administration ${ }^{13}$. Under $\mathrm{Cl}$ conditions, glutamate levels rapidly increase in the extracellular space and decrease with reperfusion. The increased concentration in the extracellular space is due to facilitated release and/or to reduced reuptake and to the fact that, despite the increase of glutamate in cerebral ischemia, the glutamate $x$ neuronal injury relation has not been well established ${ }^{29}$. The present results showed that, 48 hours after surgery, total glutamate concentrations were elevated in the two brain hemispheres of the animals treated with ketoprofen (ischemic and sham subgroups). This fact was probably due to an action of ketoprofen on the metabolic pool of glutamate, an idea supported by the similar values in the two hemispheres. After 15 days, the higher glutamate concentration in the ischemic hemisphere of treated than not treated rats can be explained by the production of this NT by in- flammatory cells, which are numerous in this phase, and/or perhaps by lower cell destruction.

NP drugs are those that reduce excitotoxicity, opposing the excessive release of excitatory amino acids and their intracellular effects ${ }^{30}$. Among those most intensely studied are the antagonists of the NMDA receptors of glutamate, among them ketoprofen. Experimental studies with transitory focal ischemia conducted at our institution have demonstrated the NP effect of ketoprofen on the rabbit retina ${ }^{31}$ and on the rat brain ${ }^{13}$. We did not find report on a NP ketoprofen dosage and opted to adopt the dosage used in a previous study ${ }^{13}$. Obviously, more studies aiming to evaluate more safety the temporal behavior of the ischemic lesion, as well as, posologic adjustments adequate to each situation. The present results did not confirm the NP effect of ketoprofen, a fact that may be explained by the use of different experimental models of ischemia (transient vs. definitive occlusion of the MCA) and due to the different postischemic periods (early vs. delayed observation).

Histopathological analysis of the sections by the Giemsa method was satisfactory for the anatomical delimitation of the lesions and agreed with literature reports. In addition, it permitted a qualitative evaluation of the injured areas at two different times of $\mathrm{Cl}$ evolution.

In conclusion, permanent focal ischemia induced in rats by coagulation of the MCA produced a constant ischemic injury in the premotor, motor and sensory cortex and in the lateral caudate-putamen region. Ischemic animals suffered behavioral changes (reduction of defecation and of exploratory activity) during the first postoperative days and presented concordant histopathological alterations that were not prevented by the use of ketoprofen. Forty-eight hours after surgery, the cerebral levels of total glutamate were more elevated in the treated animals, probably due to the action of ketoprofen on the metabolic glutamate pool.

\section{REFERENCES}

1. Tamura A, Graham DI, Mcculloch J, Teasdale GM. Focal cerebral ischemia in the rat: I. Description of technique and early neuropathological consequences following middle cerebral artery occlusion. J Cereb Blood Flow Metab 1981;1:53-60.

2. Ginsberg MD, Busto R. Rodent models of cerebral ischemia. Stroke 1989; 20:1627-1642.

3. Paxinos, G. The rat nervous system. 2.Ed. San Diego: Academic Press, 1995.

4. Silva MN. Contribuição ao estudo morfológico do círculo arterioso do cérebro (polígono de Willis) de ratos. Dissertação, Ribeirão Preto, 1998

5. Ridenour TR, Warner DS, Todd MM, Baker MT. Effects of ketamine on outcome from temporary middle cerebral artery occlusion in the spontaneously hypertensive rat. Brain Res 1991;565:116-122.

6. Wahl F, Allix M, Plotkine M, Boulu RG. Neurological and behavioral outcomes of focal cerebral ischemia in rats. Stroke 1992;23:267-272. 
7. Graham SH, Chen J. Limiting ischemic injury by inhibition of excitatory amino acid release. J Cereb Blood Flow Metab 1993;13:88-97.

8. Benveniste H, Drejer J, Schousboe A, Diemer N. Elevation of the extracellular concentrations of glutamate and aspartate in rat hippocampus during transient cerebral ischemia monitored by intracerebral microdialysis. J Neurochem 1984;43:1369-1374.

9. Phillis JW, Smith-Barbour M, Perkins LM, O'regan MH. Indomethacin modulates ischemia-evoked release of glutamate and adenosine from the rat cerebral cortex. Brain Res 1994:571:353-356.

10. McCormak K. Non steroidal anti-inflammatory drugs and spinal nociceptive processing. Pain 1994;59:9-43.

11. Woolf CJ. Generation of acute pain: central mechanisms. Br Med Bull $1991 ; 47: 523-533$.

12. Asanuma M, Asanuma S, Gómez-Vargas M, Yamamoto M, Ogawa ND. Ketoprofen, a non-steroidal anti-inflammatory drug prevents the late onset of muscarinic receptors in gerbils hippocampus after transient forebrain ischaemia. Neurosci Lett 1997;255:193-204.

13. Dias LAA, Colli BO, Netto JC, Lachat JJ. Avaliação da isquemia cerebral focal induzida pela oclusão da artéria cerebral média e a ação neuroprotetora do cetoprofeno em ratos. Arq. Neuropsiquiatr 2000;58:1047-1054.

14. Morton DB. The animals (Scientific Procedures) act 1986 and research into anaesthesia. Br J Anaesth 1990;65:303-305.

15. Flecknell PA. Anaesthesia of animals for biomedical research. Br J Anaesth 1993;71:885-894.

16. Coimbra NC, Freitas RL, Savoldi M, et al. Opioid neurotransmission in the post-ictal analgesia: involvement of $\mu_{1}$-opioid receptor. Brain Res 2001;903:216-221.

17. Bederson JB, Pitts LH, Tsuji M, Nishimura MC, Davis RL, Bartkowski H. Rat middle cerebral artery occlusion: evaluation of the model and development of a neurological examination. Stroke 1986;17:472-476.

18. Shiraishi K, Simon RP. A model of proximal middle cerebral artery occlusion in rat. J Neurosci Meth 1989;30:169-174.

19. Silva MN. Avaliação do efeito neuroprotetor do ketoprofen em ratos submetidos à isquemia encefálica focal permanente. Tese. Ribeirão Preto, 2003.

20. Carlotti CG Jr, Colli BO, Kazuo JY. Avaliação da isquemia cerebral pela respiração mitocondrial: modelo experimental. Arq Neuropsiquiatr 2002;59:335-371.

21. Lindroth P, Mopper K. High performance liquid chromatographic determination of subpicomole amounts of amino acids by precolumn derivatization with o-phtalaldehyde (OPA). Anal Chem 1979;51:1667-1674.

22. Paxinos G, Watson C. The rat brain in stereotaxic coordinates, 3.Ed. Sydney, Academic Press, 1997.

23. Colli BO, Silva MN, Carlotti CG Jr. Isquemia cerebral experimental. In Silva OC Jr, Zucoloto S, Beer A Jr (Eds). Modelos experimentais de pesquisa em cirurgia. São Paulo: Editora Robe, 1998:643-662.

24. Jiang N, Chopp M, Stein D, Feit H. Progesterone is neuroprotective after transient middle cerebral artery occlusion in male rats. Brain Res 1996; 735:101-107.

25. Lei B, Cottrell JE, Kass I.S. Neuroprotective effect of low-dose lidocaine in a rat model of transient focal cerebral ischemia. Anesthesiology 2001; 95:445-451.

26. Robinson RG. Differential behavior and biochemical effects of right and left hemispheric infarction in the rat. Science 1979;205:707-710.

27. Coutinho-Netto J, Abdul-Ghani AS, Collins JF, Bradford HF. Is glutamate a trigger factor in epileptic hyperactivity? Epilepsia 1981;22:289-296.

28. Baker CJ, Fiore AJ, Frazzini VI, Choudhri TF, Zuby GP, Solomon RA. Intraischemic hypothermia decreases the release of glutamate in the cores of permanent focal cerebral infarcts. Neurosurgery 1995;36:994-1002.

29. Nishizawa Y. Glutamate release and neuronal damage in ischemia. Life Sci 2001;69:369-381.

30. Gagliardi, R.J. Neuroprotection, excitotoxicity and NMDA antagonists. Arq Neuropsiquiatr 2000;58:583-588.

31. Santos WA. Aspectos bioquímicos e morfológicos da isquemia e reperfusão retiniana: estudo sobre a toxicidade excitatória, seus antagonistas e outros mediadores da lesão neuronal isquêmica. Tese. Ribeirão Preto, 1999. 